\title{
Olhares sobre as mulheres amazônicas segundo Elizabeth Agassiz em Viagem ao Brasil (1865-1866)
}

SILVA, Priscilla Lima da ${ }^{1}$ SOARES, Artemis de Araújo ${ }^{2}$

Resumo: Elizabeth Agassiz, mulher, naturalista cronista da Expedição Thayer (186566) que viajou pelo Brasil Imperial, do Rio de Janeiro ao Amazonas, com o objetivo de realizar um levantamento biogeográfico. No entanto, Elizabeth foi responsável por uma das primeiras crônica sociais sobre a Amazônia em que a mulher possui cores e forma.

Palavras-chave: Mulheres amazônicas, Expedições no Brasil Império, Estrutura Sociocultutural amazônica.

\section{O caminho da ideia...}

A partir da leitura do capítulo Um olhar feminino sobre a terra e a gente do Brasil do Renan Freitas Pinto, em seu livro Viagem das Ideias, publicado pela Valer, esboçou-se uma reflexão acerca do trabalho e do olhar de Elizabeth Agassiz sobre a Amazônia, em sua viagem pelo Brasil (Sudeste -Rio de Janeiro, Nordeste e Amazônia), denominada Expedição Thayer - 1865-66. A presença de Elizabeth já se constituía como uma inovação, pois em nenhuma das expedições pensadas e financiadas por Dom Pedro havia a presença de mulheres como companhia, e nesse caso específico, Elizabeth fazia parte do corpo da expedição como cronista e relatora da viagem.

\footnotetext{
${ }^{1}$ Mestranda do Programa Sociedade e Cultura na Amazônia da UFAM. Analista Legislativa da Assembleia Legislativa do Amazonas. E-mail: priscilla.limas@gmail.com

2 Doutora do Programa de Pós-Graduação em Sociedade e Cultura na Amazônia - PPGSCA/UFAM, Diretora da faculdade de Educação Física e Fisioterapia - FEFF/UFAM. E-mail: artemisoares@yahoo.com.br
} 
UNIVERSIDADE FEDERAL DO AMAZONAS

INSTUTO DE CIÊNCIAS HUMANAS E LETRAS - ICHL

PROGRAMA DE PÓS-GRADUAÇÃO EM SOCIEDADE E CULTURA NA AMAZÔNIA - PPGSCA

Naturalista e defensora da educação feminina organizou a primeira escola feminina, em sua casa em Cambridge, a qual funcionou no período de 1855 a 1863 . Foi Elizabeth Agassiz que em 1879, ajudou a fundar "Harvard anexo" em Cambridge e foi nomeada presidente da então Sociedade para a Instrução da Colegiada de Mulheres, após sua incorporação oficial à Universidade de Havard.

Contudo seu olhar e sua percepção foi profundamente modificada ao longo da Expedição Tahyer, a qual iniciou-se no ano de 1865, com uma Elizabeth Agassiz fortemente marcada por seu preconceito e fundamentos morais construídos em uma sociedade sexista, patriarcal e protestante e, encerrou-se no ano seguinte (1866) já com uma outra Elizabeth Agassiz, esta olhando a sociedade sob uma nova perspectiva, mais feminista, percursora de uma sociedade capaz de equacionar as diferenças e os direitos entre os gêneros e as classes sociais.

Essa mudança foi percebida no relato da expedição construído por Elizabeth Agassis e publicada como o livro Viagem ao Brasil, de uma cronista ocupada com as belezas naturais e a comprovação das teorias anti-evolucionista, passou a uma cronista com olhares sobre a organização social no Brasil e as diferentes funções que a mulher exercia, bem como os diferentes níveis de liberdade que estas possuíam ao longo dos diferentes espaços percorridos pela expedição capitaneada por seu marido Louis Agassiz.

\section{Elizabeth Agassiz por Renan Freitas Pinto}

No capítulo Um olhar feminino sobre a terra e a gente do Brasil de Renan Freitas Pinto, ele apresenta o trabalho de Elizabeth Agassiz enquanto naturalista e seu olhar feminino sobre a condição da mulher em um Brasil Imperial colonizado por europeus e habitado por uma mescla cultural que forjou características próprias aos sujeitos e em especial às mulheres na Amazônia e no Brasil Império.

Os relatos da cronista Agassiz abandonou a descrição naturalista e pitoresca e ocupou-se da análise da situação social dos sujeitos ocupantes do espaço e em especifico da mulher nos diferentes ambientes, e o livre trânsito delas no espaço social 
UNIVERSIDADE FEDERAL DO AMAZONAS

INSTUTO DE CIÊNCIAS HUMANAS E LETRAS - ICHL

PROGRAMA DE PÓS-GRADUAÇÃO EM SOCIEDADE E CULTURA NA AMAZÔNIA - PPGSCA

brasileiro, seja no Sudeste, no nordeste ou no norte brasileiro, que foi o caminho da expedição, transpareceu os valores de estruturas sociais, que foram construídos em uma situação colonial, escravista e patriarcal.

O contraponto foi feito no norte, na Amazônia, onde Elizabeth pôde comparar a diferença entre a vida cotidiana das mulheres das grandes e pequenas cidades brasileiras, e vida nas pequenas cidades e vila do Amazonas, marcado por um cotidiano de práticas étnicas específicas, onde as divisões de gênero diferiam da sua sociedade de origem.

\section{Relatos de Viagem pelo Brasil de John e Elizabeth Agassiz}

Livro publicado a partir do diário de campo organizado durante a expedição Thayer (1865-66), que viajou pelo Brasil, do Rio de Janeiro ao Amazonas, passando pelo nordeste, com o objetivo de fazer um levantamento biológico e geologico, propondo uma biogeografia brasileira, a pedido do Imperador Dom Pedro.

A expedição de característica naturalista, com fundamentação teórica anti darwinista, estruturou-se a partir de uma episteme catastrofista, fundamentando uma crítica sobre a mistiçagem racial a qual fortalecia um campo político de parte da elite norte-americana partidária da segregação social entre negros e brancos.

\section{Amazônia por Elizabeth Agassiz}

Ao longo do Século XVII e XVII, o imaginário ocidental sobre a Amazônia organizava-se a partir dos conceitos de exótico e de exuberância, pois as primeiras expedições de prospecção eram registradas por uma ótica pitoresca, registrando a exuberante diferença natural e os exóticos e selvagens habitantes, necessitados de educação civilizatória e cristã.

Contudo ao longo dos anos e das expedições feitas ao Brasil e por todo o processo de colonização sofrido, no século XIX, no período Imperial, em que foi 
UNIVERSIDADE FEDERAL DO AMAZONAS

INSTUTO DE CIÊNCIAS HUMANAS E LETRAS - ICHL

PROGRAMA DE PÓS-GRADUAÇÃO EM SOCIEDADE E CULTURA NA AMAZÔNIA - PPGSCA

realizada a Expedição de Agassiz, as populações amazônicas já haviam sido destruídas social e fisicamente; e os que restavam encontraram estratégias de convivência adaptando-se aos costumes colonializadores. No que tange ao aspecto natural a Amazônia foi palco das coletas zoológicas mais significantes para comprovação das teorias criacionistas do casal Agassiz.

O desencontro com o exótico e selvagem e o encontro com a nova organização social e os diferentes papéis ocupados pelas mulheres na sociedade brasileira, promovido por uma série de fatores sociohistóricos, dentre eles a Guerra do Paraguai e as diferentes formas de divisão do trabalho por gênero.

As diferenças sociais observadas por Elizabeth Agassiz, em específico a liberdade que a mulher amazônica usufruía, no que tange as práticas corporais cotidianas e as morais e práticas sexuais, desencadearam uma inversão da relação sujeito-objeto. Agassiz passou a repensar a sua identidade, sua função social e sua visão de mundo, construindo-se a partir do outro, remontando as suas próprias crenças e valores.

O processo de repensar-se enquanto sujeito na construção do diário de campo fez com que Elizabeth Agassiz "se compreende diante da obra" (Paul Ricour,1977), reposicionado seu olhar e revendo seus conceitos sobre as regras morais e as organizações sociais.

Segundo a própria Agassiz observou que "a mulher, nessa parte do Império [Amazonas], se embota no topor duma existência inteiramente vazia e sem objetivo, ou se irrita contra suas cadeias e sua infidelidade" (Agassiz, 1867:167), fazendo um contraponto entre a vida das mulheres que convivam na sociedade e as mulheres mestiças que precisam tomar a frente da família, da produção de renda e consequentemente de sua liberdade moral, incluindo no que tange aos costumes sexuais. 
UNIVERSIDADE FEDERAL DO AMAZONAS

INSTUTO DE CIÊNCIAS HUMANAS E LETRAS - ICHL

PROGRAMA DE PÓS-GRADUAÇÃO EM SOCIEDADE E CULTURA NA AMAZÔNIA - PPGSCA

\section{Mulheres na Amazônia: a condição feminina, autonomia, moralidade e civilização}

Conforme já exposto, a sociedade do século XIX preconizava o controle sobre os corpos e sobre a intimidade como regra social, e expressou a condição sine qua non da moralidade como balizador desse projeto civilizatório nos trópico, que sob o olhar da expedição Thayer acima dos trópicos havia uma liberdade excessiva. Como exemplo de decência, Elizabeth Agassiz descreveu o comportamento dos Mundurucu, encontrados na hoje região do município de Maués.

Ao longo do relato em Viagem ao Brasil (1867), a preocupação da cronista repousava sobre o embate entre as temáticas mestiçagem e pureza da raça, usando a Amazônia como contra exemplo cultural e racial, que deveria ser evitado pela América do Norte (Kury, p. 08), a crítica ao modelo de colonização centrada na escravidão negra e indígena recebeu lugar de destaque na obra do casal Agassiz.

Ao encontrar uma Amazônia cuja regra moral possuía outra estrutura, na qual o casamento para geração de filhos legítimos e vestimenta não eram temas para as pequenas cidades e vilas amazônicas. As mulheres amazônidas possuíam uma liberdade impensada na sociedade norte americana, essas mulheres iam à roça e trabalhavam sozinhas, deslocar-se de canoas, sem a supervisão dos homens.

No entanto, essa liberdade não significava uma equidade entre os sexos, pois foi observado a submissão com diferentes nuances e atenuações, principalmente relativas ao comportamento sexual, o que para Louis Agassiz era uma grande confusão, pois o cruzamento de raças gerava tipos como os mamelucos, cafusos, os caboclos, que nesse caso tornava impossível destrinchar ${ }^{3}$ a fim de encontrar a raça pura e original.

Outra tolerância da sociedade amazônica era o caso de mães solteiras, que geravam seus filhos e não eram exclusas do convívio social e seus filhos tinham sua concepção explicada pelo sobrenatural, como a lenda do boto e outras.

\footnotetext{
3 Termo utilizado por Louis Agassiz no Método da História Natural, utilizado para destrinchar o emaranhado dos cruzamentos interraciais.
} 
UNIVERSIDADE FEDERAL DO AMAZONAS

INSTUTO DE CIÊNCIAS HUMANAS E LETRAS - ICHL

PROGRAMA DE PÓS-GRADUAÇÃO EM SOCIEDADE E CULTURA NA AMAZÔNIA - PPGSCA

Ao observara o comportamento feminino, percebeu-se que as mulheres se equiparavam aos homens em sua força e destreza no manuseio do remo e da rede, esta habilidade corporal em muito impressionou Elizabeth, no entanto, o conceito de beleza da cronista tinha como padrão a beleza europeia e norte américa, ou seja, um padrões vitorianos, com traços femininos afilados, pele pálida e corpos cobertos por roupas e adereços, e a partir desse critérios ao observar as mulheres amazônicas, afirmou que a beleza física das mulheres estava em processo de grande degeneração, que ocorria devido ao incesto, que para o casal Agassiz, como cristãos, era pecado e a falta de beleza era uma consequência desse pecado. Ao observar grupos exogâmicos, perceberam que o grupo gerava humanos considerados melhores e desta forma classificaram a beleza como "mobilidade fisionômica e traços de amáveis suavidades".

Um dos motivos que causou a mudança na organização social e do trabalho foi a Guerra do Paraguai, que causou a ausência dos homens e forçou as mulheres a assumirem novos papéis na divisão do trabalho, assumindo o provimento da casa no comercio e também nas plantações e no extrativismo animal (pesca e caça), todas essas atividades imprimiam novas formas aos corpos femininos e também ao comportamento em sociedade.

A proximidade em convivência com as mulheres amazonenses, por meio de conversas fez com que Elizabeth se apropriasse de novos elementos para analisar as mulheres locais o que fez com que atenuasse algumas pré concepções e verdades que carregava por sua formal moral e religiosa. A partir de seu novo olhar pode perceber que se deparava com uma mulher singular, forte, responsável por seu destino e por sua própria vida, o que provocou em Elizabeth um sentimento de admiração ao afirmar nas páginas finais de sua crônica que as mulheres amazônicas vivam uma vida invejável.

No entanto, apesar de perceber que a mulher amazonense possui liberdade e em muitos momentos poder de decisão sobre si mesma, sua obra também denunciou a situação calamitosa em que essas mulheres se encontravam durante a guerra, pois apesar de ver a liberdade que estas mulheres usufruíam, ainda assim, estas mulheres sofriam com a falta de respeito e leis que lhes garantisse direitos específicos. 
UNIVERSIDADE FEDERAL DO AMAZONAS

INSTUTO DE CIÊNCIAS HUMANAS E LETRAS - ICHL

PROGRAMA DE PÓS-GRADUAÇÃO EM SOCIEDADE E CULTURA NA AMAZÔNIA - PPGSCA

\section{Desta forma...}

Elizabeth Agassiz constitui-se como novidade e revolução em seu tempo. Foi a primeira mulher a participa de uma expedição financiada pelo Império Brasileiro exercendo a função de cronista. Seu olhar de naturalista foi reconstruindo ao observar a sociedade e conseguir perceber as diferentes organizações sociais dentro de uma mesma nação, o Brasil.

Seu olhar especializou-se na observação de mulheres e suas funções sociais, mesmo construindo sua crônica a partir de seus conceitos e formação moral inicial, esta cronista foi capaz de transformar seu relato e sua compreensão acerca das condições sociais e da vida vivida pelas mulheres nesse país tropical.

Ao longo de Viagem pelo Brasil, Elizabeth reconstrói-se enquanto observadora e pensadora sobre a Amazônia. Esta cronista mudou ao longo do relato e sofreu essas mudanças ao ter seus conceitos confrontados com realidades sociais muito distintas da sua.

A grande contribuição de Elizabeth Agassiz está em olha e ver a mulher no Brasil no período imperial, percebendo seu papel e função na estrutura social e sua capacidade de continuar mesmo diante de uma sociedade tão adversa e hostil. 
UNIVERSIDADE FEDERAL DO AMAZONAS

INSTUTO DE CIÊNCIAS HUMANAS E LETRAS - ICHL

PROGRAMA DE PÓS-GRADUAÇÃO EM SOCIEDADE E CULTURA NA AMAZÔNIA - PPGSCA

\section{Referências}

KURY, Lorelai B. Viagem ao Brasil. Revista brasileira de história. Disponível em http://www.scielo.br/pdf/rbh/v21n41/a09v2141.pdf. Acesso em em 06 de abril de 2013, as 22:45.

PINTO, Renan Freitas. Viagem das Ideias. 2.ed. Manaus: Valer, 2008.p. 191-194.

SANTOS, Fabiane Vinente dos. "Brincos de ouro e saias de chita": mulher e civilização na Amazônia segundo Elizabeth Agassiz em Viagem ao Brasil (1865-1866). Disponível em http://www.arca.fiocruz.br/bitstream/icict/2729/1/brincosdeouro.pdf. em 06 de abril de 2013, as $22 \mathrm{~h}$.

THARP, Louis Salão. Aliança Aventureiro: A História da Família Agassiz de Boston (1959), disponível em http://www.women-philosophers.com/Elizabeth-Cabot-Cary-Agassiz.html, acesso em 06 de abril de 2013, as 22:30. 